\title{
ANTIBACTERIAL ACTIVITY OF THREE TOOTH-COLORED RESTORATIVE MATERIALS AGAINST STREPTOCOCCUS MUTANS: AN IN VITRO STUDY
}

\author{
Norhan A. El Dokky*, Walid A. Fouad* and Yasmine Sabry**
}

\begin{abstract}
Background: Antibacterial activity of restorative materials had an important role in preventing caries recurrence.

Aim of the study: to evaluate the antibacterial effect of three tooth-colored restorative materials.

Materials and Methods: Three commercially available tooth-colored restorative materials, GC Fuji (Group I), Riva self-cure (Group II) and Versa Comp (Group III) were evaluated. The test samples of restorative materials were manipulated in accordance with manufacturer's instructions. Eppendorf tubes were filled with constant measured amount of the three tested restorative materials; a conical cavity was created in the center of each material after curing. Bacterial suspension was prepared from fresh overnight growth of Streptococcus mutans on blood agar. $50 \mu \mathrm{L}$ of bacterial suspension was placed in the conical cavity and around the restorative material inside each eppendorf tube and then were incubated. At the end of incubation period, eppendorf tubes were removed from candle jar and viable bacterial count was estimated.
\end{abstract}

Results: It has been found that at day1, day 2 as well as day 3, there was decrease in bacterial count but, there was no statistically significant difference between the three groups. On studying each group separately, group I there was a statistically significant decrease in bacterial count at day 2 and group II and III showed statistically significant decrease from day 2 to day 3 .

Conclusions: Fuji LC was more effective against Streptococcus mutans, than Riva self-cure and Versa comp, but with no significant difference.

\section{INTRODUCTION}

Dental caries still remains a major public health problem despite the widespread use of fluoride and the decline in caries prevalence observed in the majority of highly industrialized countries. ${ }^{[1]}$ Longlasting restorations are clinically attractive because they can reduce patents' pain and expense as well as

\footnotetext{
* Associate Professor- Pediatric Dentistry and Dental Public Health- Faculty of Dentistry- Cairo University.

** Lecturer of Immunology and Microbiology- Immunology and Microbiology Department - Faculty of Medicine-

Cairo University.
} 
the number of their visits to dental office. ${ }^{[2,3]}$ Both restorative materials and oral bacteria are believed to be responsible for restoration failure. ${ }^{[3]}$

In an attempt to obtain restorative materials that could prevent marginal gaps colonization, materials capable of releasing fluoride and providing antimicrobial activity have been developed, such as; Glass Ionomer cements (GIC),"compomers" and fluoridated composite resins. ${ }^{[4,5]}$

Tooth-colored restorative materials are increasingly demanded by patients and applied by clinicians. In spite of routine use of posterior tooth-colored restorative materials, poor marginal adaptation of composite resins, mostly due to the polymerization shrinkage, is still considered a major reason for the failure of these restorations. ${ }^{[6-8]}$

Microleakage and recurrent caries are major clinical problem associated with direct posterior composite restorations. Bacterial penetration into the prepared cavity can lead to secondary caries, which is the main reason for failures in dental restorations. ${ }^{\text {[9] }}$ Due to this potentiality of leakage, any restorative /base/liner material used in the mouth should have antibacterial properties in defense against bacterial migration. ${ }^{[10]}$

Effective and long lasting antibacterial property of composite resin-restorative material may eliminate bacterial biofilm formation at the interface and thus increase restoration longevity. ${ }^{[11]}$

Several species of bacteria has been isolated from dental plaque, such as Lactobacilli, Streptococcus mutans, Streptococcus sorbinus etc, ${ }^{[12]}$ which may induce the formation of caries. Streptococcus mutans is one of the most frequent bacteria involved in dental caries. ${ }^{[13]}$

The aim of the present study was to evaluate the antibacterial effect of three tooth colored restorative materials.

\section{MATERIALS AND METHODS}

TABLE (1): Materials used in this study:

\begin{tabular}{|l|l|}
\hline \multicolumn{1}{|c|}{ Materials } & \multicolumn{1}{c|}{ Manufacturer } \\
\hline GC Fuji LC capsule VLC & GC corporation, Tokyo, Japan \\
\hline $\begin{array}{l}\text { Riva self-cure Glass } \\
\text { Ionomer capsule }\end{array}$ & SDI Limitation, Australia \\
\hline $\begin{array}{l}\text { Versa Comp universal } \\
\text { hybrid composite }\end{array}$ & Sultan \\
\hline
\end{tabular}

Three commercially available tooth-colored restorative materials were used in this study; the details of these materials were shown in table (1).

GC Fuji (Group I), Riva self-cure (Group II) and Versa Comp (Group III).

The micro-organisms used in this study were four strains of Streptococcus mutans. Bacterial plaque was collected from different parts of the patient's mouth immediately cultured on Mitis Salivarius agar kept in an incubator at $37^{\circ} \mathrm{C}$ for 24 hours; afterwards isolated and identified. Identification was accomplished by colony morphology, gram stained films, catalase test, subculture on blood agar and bile esculin agar. Pure isolates were preserved till time of experiment.

The test samples of restorative materials were manipulated in accordance with manufacturer's instructions. The samples were prepared in strip crown form (Uniteck 3M Dental products division) for standardization as pre- fabricated mould. ${ }^{[10]}$ Clean Eppendorf tubes were filled with constant measured amount of the three tested restorative materials; a conical cavity was created in the center of each material after curing by fissure stone bur number 5 . The specimens were autoclaved afterwards at $121^{\circ} \mathrm{C}$ for 30 minutes.

Bacterial suspension equivalent to $0.5 \mathrm{McFar}-$ land was prepared from fresh overnight growth of Streptococcus mutans on blood agar. ${ }^{[14]} 50 \mu \mathrm{L}$ of bacterial suspension was placed in the conical cavity and around the restorative material inside each eppendorf tube. They were then incubated in candle jar for 24, 48 and 72 hours. At the end of incuba- 
tion period, eppendorf tubes were removed from candle jar and viable bacterial count was estimated. Ten folds serial dilutions were done for each eppendorf tube (up to 1/10000) and counting was done on Mitis Slivarius agar. The number of colony forming unit (CFU) was calculated by this formula: $50 \mathrm{x}$ No. of colonies x Inverse of dilution.

\section{Statistical analysis:}

All data were collected and statistically analyzed. A logarithmic transformation (Log10 transformation) of each CFU count was performed because of the high range of bacterial counts. Data were explored for normality after Log 10 transformation using Kolmogorov-Smirnov and Shapiro-Wilk tests. Data showed non-parametric (non-normal) distribution. So, data were presented as median and range values. Kruskal-Wallis test was used to compare between the three groups. Friedman's test was used to study the changes by time in each group. Wilcoxon signed-rank test was used for pair-wise comparisons when Friedman's test is significant.

The significance level was set at $\mathrm{P} \leq 0.05$. Statistical analysis was performed with IBM ${ }^{\circ}$ SPSS $®$ Statistics Version 20 for Windows.

\section{RESULTS:}

It has been found that at day1, day 2 as well as day 3 , as regards median and range there was decrease in bacterial count but, there was no statistically significant difference between the three groups as shown in table (2) \& figure (1).

TABLE (2): Median, range values and results of comparison between $\log 10 \mathrm{CFU}$ in the three groups

\begin{tabular}{|c|c|c|c|c|}
\hline & Group I & Group II & Group III & P-value \\
\hline Day 1 & 5.2 & 5.4 & 6.5 & 0.388 \\
& $(5.0-6.1)$ & $(0.0-7.6)$ & $(5.9-6.9)$ & \\
\hline Day 2 & 0.0 & 2.0 & 4.7 & 0.396 \\
& $(0.0-4.7)$ & $(0.0-6.0)$ & $(0.0-6.9)$ & \\
\hline Day 3 & 0.0 & 0.0 & 0.0 & 0.368 \\
& $(0.0-0.0)$ & $(0.0-0.0)$ & $(0.0-3.2)$ & \\
\hline
\end{tabular}

\footnotetext{
*: Significant at $P \leq 0.05$
}

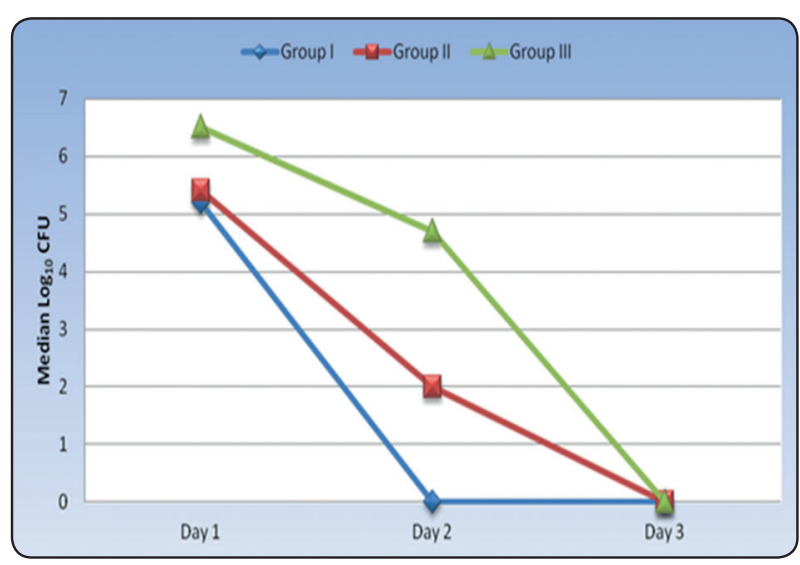

Fig. (1): Line chart representing median Log $10 \mathrm{CFU}$ in the three groups.

On studying each group separately, in group I there was a statistically significant decrease in bacterial count at day 2 and day 2 and 3 didn't show any bacterial growth, while in group II and III, there was no statistically significant decrease in bacterial count at day 2, but from day 2 to day 3 there was a statistically significant decrease in bacterial count as shown in table (3).

TABLE (3): Median, range values and results of comparison between Log10 CFU in each group at different time periods

\begin{tabular}{|c|c|c|c|}
\hline & Group I & Group II & Group III \\
\hline Day 1 & $\begin{array}{c}5.2 \\
(5.0-6.1) \mathrm{a}\end{array}$ & $\begin{array}{c}5.4 \\
(0.0-7.6) \mathrm{a}\end{array}$ & $\begin{array}{c}6.5 \\
(5.9-6.9) \mathrm{a}\end{array}$ \\
\hline Day 2 & $\begin{array}{c}0.0 \\
(0.0-4.7) \mathrm{b}\end{array}$ & $\begin{array}{c}2.0 \\
(0.0-6.0) \mathrm{a}\end{array}$ & $\begin{array}{c}4.7 \\
(0.0-6.9) \mathrm{a}\end{array}$ \\
\hline Day 3 & $\begin{array}{c}0.0 \\
(0.0-0.0) \mathrm{b}\end{array}$ & $\begin{array}{c}0.0 \\
(0.0-0.0) \mathrm{b}\end{array}$ & $\begin{array}{c}0.0 \\
(0.0-3.2) \mathrm{b}\end{array}$ \\
\hline P-value & $0.023^{*}$ & $0.045^{*}$ & $0.037^{*}$ \\
\hline
\end{tabular}

*: Significant at $P \leq 0.05$, Different superscripts in the same column are statistically significantly different

As regards the $\%$ reduction in bacterial count in the three groups results showed no statistically significant difference as shown in table (4). 
TABLE (4): Median, range values and results of comparison between \% reductions in bacterial counts in the three groups

\begin{tabular}{|c|c|c|c|c|}
\hline & Group I & Group II & Group III & P-value \\
\hline Day 1- Day2 & $100.0(45.0-100.0)$ & $98.8(0.0-100.0)$ & $98.8(0.0-100.0)$ & 0.446 \\
\hline Day 1- Day3 & $100.0(100.0-100.0)$ & $100.0(0.0-100.0)$ & $100.0(0.0-100.0)$ & 0.573 \\
\hline
\end{tabular}

$*$ : Significant at $P \leq 0.05$

\section{DISCUSSION}

Dental caries constitutes one of the most common infectious diseases. It is multi-factorial disease related to the presence of cariogenic bacteria embedded in dental plaque which is particularly Streptoccocus mutans. ${ }^{[15-16]}$ Therefore several experiments have been conducted to incorporate antibacterial agents into dental filling materials as resin composites and glass-ionomers, in order to inhibit bacterial attachment and thus plaque accumulation. ${ }^{[17-18]}$

The aim of the present study was to evaluate the antibacterial effect of three tooth colored restorative materials on four strains of mutans Streptococci.

In the present study, an assay was established to determine viable bacterial counts after incubation of small amount of bacterial suspension within the materials, designed to avoid dilution of components released from the materials. ${ }^{[19]}$ This method is more reliable than other methods as its most significant advantage is the direct contact between the bacteria and the restorative material, which simulates the oral cavity. ${ }^{[19-20]}$ Direct contact test has been widely used for evaluating antibacterial activity of different dental materials. ${ }^{[20-23]}$

Streptococcus mutans was used in this study as it is known to be the primary etiological factor for carious lesions, and routinely used in testing the antimicrobial activity of restorative materials. ${ }^{[24]}$

The antibacterial effect of the tested materials was recorded after 24, 48 and 72 hours as Malton et al; 2004, ${ }^{[20]}$ found that none of the composite resins used in their study could affect the bacterial growth immediately after polymerization.

In the current study, there was no statistically significant difference between the three tested materials at day1, 2 and 3. On the contrary Shirani et al 2008, ${ }^{[25]}$ and Luczaj-Cepowicz et al $2014,{ }^{[26]}$ revealed that there were significant differences between different materials in all the incubation periods.

On the other hand the results of the present study of each material separately showed that, regarding group I (Fuji LC), there was statistically significant decrease in bacterial count at day 2, but regarding group II ( Riva self-cure) and group III (Versa Comp) there was no statistically significant decrease in bacterial count at day 2, although from day 2 to day 3 there was statistically significant decrease in the count.

The effects of glass Ionomer based restorative materials on cariogenic bacteria are known, probably resulting from release of fluoride, [27-29] Vemeersch et al 1993, ${ }^{[30]}$ concluded that the low of bacteria, during setting may contribute more to the antibacterial properties than their fluoride leaching capabilities. Yap et al $1999,{ }^{[31]}$ reported that there was no antibacterial activity despite the presence of fluoride around the set material. However, varying results could be obtained, as it is known that the diffusibility of an antimicrobial agent depends on its size, form of filler particles, and concentration in the material. In addition, the diffusibility of ions $\left(\mathrm{F}^{-}\right.$, 
$\mathrm{Ca}^{++}, \mathrm{Al}^{+++}, \mathrm{OH}^{-}$) from glass ionomers depends on the $\mathrm{pH}$ of the environment.

In the current study the results of group III which represents the composite is nearly similar to group II which represents the glass Ionomer, as it showed antibacterial activity comparable to group II, these results are in contrast to a study carried out by Matalon et al $2004,{ }^{[20]}$ who revealed that no antibacterial activity is attributed to polymerized composite resins, however the results of present study regarding the antibacterial activity of composite may be due to the presence of barium boron fluro-alumino silicate. On the contrary, Shirani et al 2008, ${ }^{[25]}$ concluded that fluoride release from composite resins enriched with fluoride is less than that from glass Ionomer.

\section{CONCLUSIONS:}

Based on the results of the present study, it can be concluded that Fuji LC was more effective against Streptococcus mutans, than Riva self-cure and Versa comp, but with no significant difference, this activity appears to be variable and dependent on factors such as the chemical composition, low $\mathrm{pH}$, release of $\mathrm{F}^{-}$, and other ions from the restorative materials. Thus, it can be established with the continuous urge for novelties in dentistry, ranging from changing professional perceptions to altering demands from the patient and the enormous progress in material sciences, the quest for an ideal aesthetic biomimetic restorative material still continues. Further, research regarding these bioactive materials is still required.

\section{RECOMMENDATIONS}

1- More specific and more sensitive trials are required to determine the materials' constituents responsible for the antibacterial activity.

2- Further studies are suggested to be undertaken covering other materials and a larger number of cariogenic bacteria.
3- Further studies are suggested to be done covering a longer incubation period.

\section{REFERENCES}

1. Marthaler TM. Changes in dental caries. Caries Res 2004; 38: 173-181.

2. Major IA, Dahl JE, Moorhead JE. Placement and replacement of restorations in primary teeth. Acta Odontol Scand 2002; 60(1): 25-28.

3. Forss H, Widstrom E. Reasons for restorative therapy and longevity of restorations in adults. Acta Odontol Scand 2004; 62(2): 82-86.

4. Frencken JE, Holmgren CJ. Atraumatic restorative treatment (ART) for dental caries. 1st ed. Nijmegen (the Netherlands): STI Books 1999.

5. Phantumvanit P, Songpaisan Y, Pilot T, Frencken JE. Atraumatic restorative treatment (ART): a three-year community field trial in Thailand -survival of one surface restorations in the permanent dentition. J Public Health Dent 1996; 56: 141-145.

6. Haller B, Trojanski A. Effect of multi-step dentin bonding systems and resin modified glass ionomer cement liner on marginal quality of dentin-bonded resin composite Class II restorations. Clin Oral Investig 1998; Sep; 2(3):130 136.

7. Kuramoto A, Imazato S, Walls AW, Ebisu S. Inhibition of root caries progression by an antibacterial adhesive. J Dent Res 2005; Jan; 84(1): 89-93.

8. Ferdianakis K. Microleakage reduction from newer esthetic restorative materials in permanent molars. J Clin Pediatr Dent 1998; Spring; 22(3): 221-229.

9. Gaengler P, Hoyer I, Montag R. Clinical evaluation of posterior composite restorations: the 10 year report. J Adhes Dnt 2001; 3(2): 185-194.

10. Suresh N, Sureshchandra B. Antibacterial efficacy of glass ionomers, composite resin, liners and polycarboxylates against selected stock culture microorganisms: An in vitro study. Indian Endodon Soc 2012; 24(2): 21-28.

11. Ebi N, Imazato S, Noiri Y, Ebisu S. Inhibitory effects of resin composite containing bactericide-immobilized filler on plaque accumulation. Dent Mater 2001; 17: 485-491.

12. Houte JV. Role of micro-organisms in caries etiology. J Dent Res 1994; 73(2): 672-681. 
13. Vermeersch G,Leloup G, Delmee M, Vreven J. Antibacterial activity of glass ionomer cements, compomers and resin composites: relationship between acidity and material setting phase. J Oral Rehab 2005; 368-374.

14. MurrayPR, Chapin KC. Reagants, stain and media. In: Manual of clinical microbiology. Murray PR, Baron EJ, PfallerMA, Tenover FC, Yolken RH, editors. $7^{\text {th }}$ edition. American Society of Microbiology; Washington DC 2005; 1663-1708.

15. Carvalho JC, Ekstrand KR, Thylstrup A. Dental plaque and caries on occlusal surfaces of first permanent molar in relation to stage of eruption. JDental Res 1989; 68: 773-779.

16. Powell LV. Caries prediction: a review of the literature. Comm Dent Oral Epidemiol 1998; 26: 361-371.

17. Ehara A, Torii M, Imazato S, Ebisu S. Antibacterial activities and release kinetics of a newly developed recoverable controlled agent-release system. J Dent Res 2000; 79: 824828 .

18. Sterinberg D, Moldovan M, Molukandov D. Testing a degradable topical varnish of cetylpyridinium chloride in an experimental dental biofilm modle. J Antimicrob Chemother 2001; 48: 241-243.

19. Boeckh C, Schumacker E, Podbielski A, Haller B. Antibacterial activity of restorative dental biomaterials in vitro. Caries Res 2002; Mar-Apr; 36(2): 101-107.

20. Matalon S, Slutzky H, Weiss EI. Surface antibacterial properties of packable resin composites: part I. Quintessence Int 2004; Mar; 35(3): 189-193.

21. Matalon S, Slutzky H, Weiss EI. Antibacterial properties of 4 orthodontic cements. Am J Orthod Dentofacial Orthop $2005 ; 127(1) ; 56-63$.

22. Slutsky H, Weiss EI, Lewinstien I, Slutzky S, Matalon S. Surface antibacterial properties of resin and resin-modified dental cements. Quintessence Int 2007; 38: 55-61.
23. Matalon S, Weiss EI, Gozaly N, Slutzky H. Surface antibacterial properties of compomers. Eur Arch Paediatr Dent 2006; 136-141.

24. Slutzky H, Matalon S, Weiss EI. Antibacterial surface properties of polymerized single-bottle bonding agents: part II. Quintessence Int 2004; 35: 275-279.

25. Shirani F, Havaei A, Maleekipour M, Sharafi M. Surface antibacterial properties of four tooth-colored restorative materials. J of Dentist 2008; 5(1): 1-6.

26. Łuczaj-Cepowicz E, Marczuk-Kolada G, Zalewska A, Pawińska M, Leszczyńska K. Antibacterial activity of selected glass Ionomer cements. Postepy Hig Med Dosw (online) 2014; 68:23-28.

27. Herrera M, Castillo A, Bravo M, Liebana J, Carrion P. Antibacterial activity of resin adhesives, glass Ionomer and resin-modified glass Ionomer cements and a compomer in contact with dentin caries samples. Oper Dent 2000; 25(4): 265-269.

28. Torii Y, Itoota T, Okamoto M, Nakabo S, Nagamine M, Inoue K. Inhibition of artificial secondary caries in root by fluoride-releasing restorative materials. Oper Dent 2001; 26(1): 36-43

29. Wiegand A, Buchalla W, Attin T. Review on fluoride-realsing restorative materials-fluoride release and uptakecharacteristics, antibacterial activity and influence on caries formation. Dent Mater 2007; 23(3): 343-362.

30. Vermeersch KL, de Soet JJ, van Amerongen WE, de Graaff J. The effect of glass-ionomer on carious dentine: An in vivo study. Caries Res 1993; 27: 417- 423.

31. Yap AU, Khor E, Foo SH. Fluoride release and antibacterial properties of new-generation colored restoratives. Oper Dent 1999; 24: 297-305. 